\title{
Anticorrosion Behaviour of SS304 Microgroove Surfaces in Saline Water
}

\author{
Vivek Anand Annakodi ${ }^{1}$, Ramachandra Arvind Singh ${ }^{2, *}$, Subramanian Jayalakshmi ${ }^{2, * \mathbb{D},}$, Yupeng Zhang ${ }^{2}$, \\ Koppula Srinivas Rao $^{3}$ and Rajashekhara Shabadi ${ }^{4, *}$
}

check for updates

Citation: Annakodi, V.A.; Arvind Singh, R.; Jayalakshmi, S.; Zhang, Y.; Srinivas Rao, K.; Shabadi, R. Anticorrosion Behaviour of SS304 Microgroove Surfaces in Saline Water. Metals 2021, 11, 1543. https:// doi.org/10.3390/met11101543

Academic Editor: Heon-Young Ha

Received: 14 August 2021

Accepted: 23 September 2021

Published: 28 September 2021

Publisher's Note: MDPI stays neutral with regard to jurisdictional claims in published maps and institutional affiliations.

Copyright: (c) 2021 by the authors. Licensee MDPI, Basel, Switzerland. This article is an open access article distributed under the terms and conditions of the Creative Commons Attribution (CC BY) license (https:/ / creativecommons.org/licenses/by/ $4.0 /)$.
1 Department of Aeronautical Engineering, MLR Institute of Technology, Hyderabad 500043, India; vivekanandbit@gmail.com

2 School of Mechanical and Electrical Engineering, Wenzhou University, Wenzhou 325035, China; ypzhang25@gmail.com

3 Department of Computer Science and Engineering, MLR Institute of Technology, Hyderabad 500043, India; ksreenu2k@gmail.com

4 UMR 8207-UMET-Unité Matériaux et Transformations, University Lille, CNRS, INRAE, Centrale Lille, F-59000 Lille, France

* Correspondence: r.arvindsingh@gmail.com (R.A.S.); jayalakshmi.subramanian@gmail.com (S.J.); rajshekhara.shabadi@univ-lille.fr (R.S.); Tel.: +91-956-678-4064 (R.A.S.); +91-956-678-4068 (S.J.); +33-699-212-594 (R.S.)

\begin{abstract}
The 304 Stainless Steel (SS304) is severely affected by salt water corrosion due to its high surface wettability. By reducing its surface wettability, its corrosion can be reduced. To achieve this, topographical modification of the steel surface is an effective route. In this work, SS304 flat surfaces were topographically modified into microgrooves (ridge width $250 \mu \mathrm{m}$ to $500 \mu \mathrm{m}$, groove width $200 \mu \mathrm{m}$, width ratio = ridge width/groove width >1). Wire cut electrical discharge machining was used to fabricate the microgrooves. Long-term wetting characteristics and long-term corrosion behaviour of flat surface and microgrooves were studied. The influence of the nature of wetting of the tested surfaces on their corrosion behaviour was examined. The sessile drop method and potentiodynamic polarization tests in sodium chloride $(3.5 \mathrm{wt} . \% \mathrm{NaCl}$ ) solution (intermittent and continuous exposures for $168 \mathrm{~h}$ ) were studied to characterize their wetting and corrosion behaviours, respectively. Topographical modification imparted long-term hydrophobicity and, as a consequence, long-term anticorrosion ability of the steel surface. Micropatterning reduced the corrosion rate by two orders of magnitude due to reduction in interfacial contact area with the corrosive fluid via composite wetting, i.e., solid-liquid-air interface. Microgrooves showed corrosion inhibition efficiency $\geq 88 \%$, upon long-term exposure to $\mathrm{NaCl}$ solution. By comparing the wetting and corrosion behaviours of the microgrooves with those of the previously studied microgrooves (ridge width/groove width $<1$ ), it was found that the surface roughness of their ridges strongly influences their wetting and corrosion properties.
\end{abstract}

Keywords: 304 stainless steel; microgrooves; wettability; corrosion; saline water; surface roughness

\section{Introduction}

Topographical modification of surfaces is relatively a new approach in the field of corrosion prevention, compared to coating, plating, painting, nhibitor, cathodic protection and microstructure modification [1,2]. Topographical modification involves creating geometrical patterns on metallic surfaces that induce antiwetting ability and consequently alleviate liquid mediated corrosion. Patterns are multi-functional. They can be utilized for more than one purpose in combination with their anticorrosion functionality, such as antifriction, antifouling, antifrosting/icing, drag reduction etc. [3-5].

Micropatterns can be incorporated in situ/post-manufacturing stage of components via chemical etching [6], machining methods such as laser techniques [7-10], focused 
ion beam method [11], electrochemical process [12], mechanical machining, e.g., grinding [13], micromachining, e.g., wire electrical discharge machining [14], ultrasonic elliptical vibration cutting [15], etc. With the advancement in additive manufacturing technology, metallic components can be printed and finished with micropatterns on their surfaces in a one-step process. As an example, Figure 1 shows 316L micropatterns printed by the binder jetting (BJ) additive manufacturing technology [16]. Such printing of micropatterns gives the capability to realize anticorrosion surfaces on components without additional machining/processing.

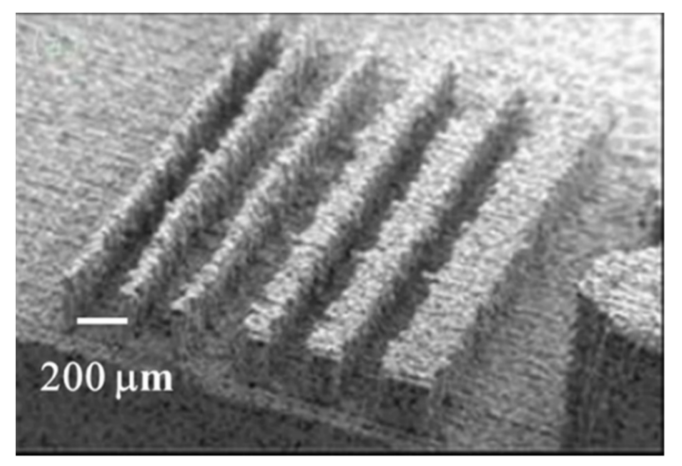

Figure 1. The 316L micropatterns printed by binder jetting (BJ) additive manufacturing technology [16].

Topographical modification provides several advantages, such as ease of making patterns due to their geometrical nature, well-established processes to make patterns, absence of interface and complex chemistry etc. Topographical modifications via geometrical patterning of metallic surfaces can effectively reduce liquid mediated corrosion, and examples include: laser generated micropillars on aluminium surfaces [7], laser ablated micro-holes on nickel surfaces [8], micro-holes on biomedical devices created by focused ion beam [11], laser textured SS316L surfaces [9], microchannels fabricated by chemical etching on SS304 surfaces [6] and laser treatment of $\mathrm{Al} 7075$ aluminium alloy to form microgrooves with hierarchical roughness [10]. However, these studies are restricted to one-time testing and do not report on the long-term corrosion behaviour of the topographically modified surfaces, which is important for application purposes.

In this work, 304 stainless steel (SS304) flat surfaces were topographically modified into microgrooves. Long-term wetting characteristics and long-term corrosion behaviour of the modified surfaces were studied. The aim of the investigation was to examine the efficacy of geometrical patterns to impart long-term anticorrosion ability. SS304 is a widely used engineering material with application in mechanical/architectural structures, food processing equipment, biomedical, automobile and aerospace sectors [17]. Although the steel has good resistance to chemicals due to chromium, it is severely affected by aggressive chloride ions in salt water, which is aggravated due to its high surface wettability $[18,19]$. Hence, reducing wettability of the steel surface is a solution to reduce the severity of salt water corrosion. Thereby, the utility and performance of the steel can be extended in humid/marine environments.

\section{Materials and Methods}

As-received SS304 steel surfaces were polished using silicon carbide abrasive papers of different grades (80, 120, 220, 400, 600, 1000, 2000 grit size), followed by diamond polishing. The surfaces were cleaned with acetone to remove debris. Average surface roughness of the polished surfaces was $0.015 \mu \mathrm{m}$, as measured using a 3D optical profilometer (WYKO NT1100, Champaign, IL, USA). These surfaces were taken as the reference surface, herewith referred to as SS304 flat surface. SS304 flat surface and topographically modified SS304 flat surface in the form of microgrooves were taken as the test surfaces. 
Wettability test and corrosion test were conducted for the surfaces in three different ways:

(1) Wettability test, followed by corrosion test.

(2) Intermittent exposure to sodium chloride $(\mathrm{NaCl})$ solution for $168 \mathrm{~h}$ (wettability measured at an interval of every $24 \mathrm{~h}$ ), followed by corrosion test.

(3) Continuous exposure to $\mathrm{NaCl}$ solution for $168 \mathrm{~h}$ (wettability measured at an interval of every $24 \mathrm{~h}$ ), followed by corrosion test.

\subsection{SS304 Microgroove Surfaces}

Microgrooves (MG) with constant height $(100 \mu \mathrm{m})$, constant groove width $(200 \mu \mathrm{m})$ and varying ridge width $(250 \mu \mathrm{m}, 300 \mu \mathrm{m}, 400 \mu \mathrm{m}$ and $500 \mu \mathrm{m})$ were machined on SS304 flat surfaces by wire cut electrical discharge machining (WEDM). A tungsten electrode of $0.18 \mathrm{~mm}$ diameter was used as the slicing wire. The spark gap between the wire and workpieces was maintained at $0.02 \mathrm{~mm}$. Set process parameters were: peak current $3 \mathrm{~A}$, pulse on time $15 \mu \mathrm{s}$, pulse off time $4 \mu \mathrm{s}$, gap voltage $100 \mathrm{~V}$ and cutting speed $2.23 \mathrm{~mm} / \mathrm{min}$.

Geometrical parameters of microgrooves, namely: ridge width $\left(\mathrm{W}_{\mathrm{r}}\right)$, groove width $\left(\mathrm{W}_{\mathrm{g}}\right)$ and groove depth $\left(\mathrm{D}_{\mathrm{g}}\right)$ are illustrated in Figure $2 \mathrm{a}$. The width ratio $\left(\mathrm{WR}=\mathrm{W}_{\mathrm{r}} / \mathrm{W}_{\mathrm{g}}\right)$ of MG was kept $>1$, such that $W_{r}>W_{g}$. Nomenclature and geometrical parameters of MG are mentioned in Table 1. A scanning electron microscope (SEM) image of MG1 is shown in Figure 2b. An optical microscope image of a ridge surface of MG1 is shown in Figure 2c. Average surface roughness on the ridges of MG was $4.85 \mu \mathrm{m}$, as measured using a 3D optical profilometer (WYKO NT1100, Champaign, IL, USA). Surface roughness on the ridges is due to the WEDM machining process [20].

(a)

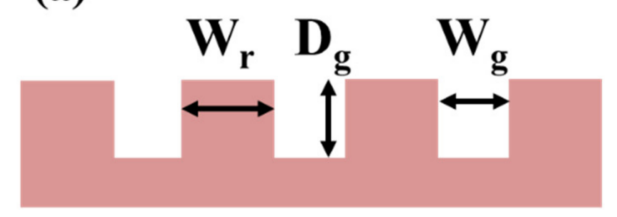

(c)

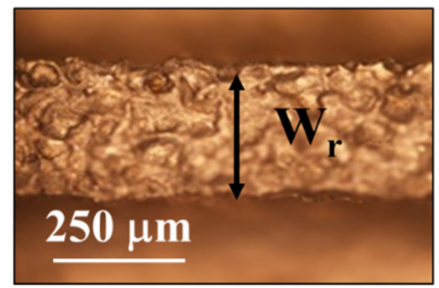

(b)

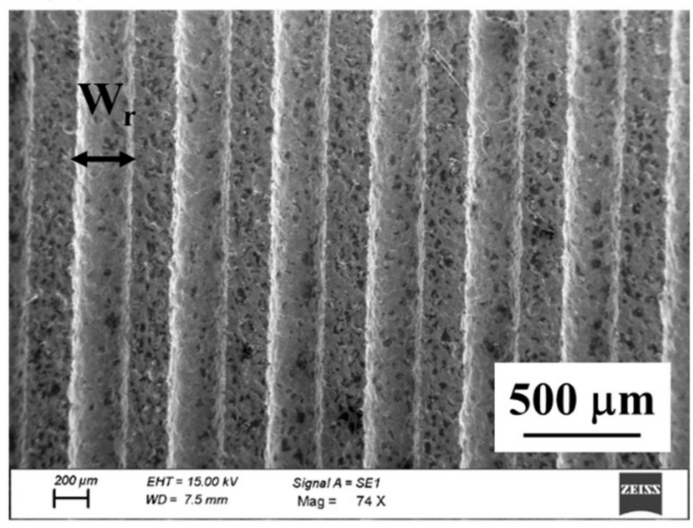

Figure 2. (a) Geometrical parameters of MG: ridge width $\left(\mathrm{W}_{\mathrm{r}}\right)$, groove width $\left(\mathrm{W}_{\mathrm{g}}\right)$ and groove depth $\left(D_{g}\right)$. (b) SEM image of MG1 and (c) optical microscope image of a ridge surface of MG1.

Table 1. Nomenclature and geometrical parameters of MG.

\begin{tabular}{ccccc}
\hline Surface & $\begin{array}{c}\text { Ridge Width } \\
\left(\mathbf{W}_{\mathbf{r}}\right)(\boldsymbol{\mu m})\end{array}$ & $\begin{array}{c}\text { Groove Width } \\
\left(\mathbf{W}_{\mathbf{g}}\right)(\boldsymbol{\mu \mathbf { m }})\end{array}$ & $\begin{array}{c}\text { Groove Depth } \\
\left(\mathbf{D}_{\mathbf{g}}\right)(\boldsymbol{\mu} \mathbf{m})\end{array}$ & $\begin{array}{c}\text { Width Ratio } \\
\mathbf{W R}=\mathbf{W}_{\mathbf{r}} / \mathbf{W}_{\mathbf{g}}\end{array}$ \\
\hline MG1 & 250 & 200 & 100 & 1.25 \\
MG2 & 300 & 200 & 100 & 1.5 \\
MG3 & 400 & 200 & 100 & 2 \\
MG4 & 500 & 200 & 100 & 2.5 \\
\hline
\end{tabular}

\subsection{Wettability Test}

Surfaces were cleaned with acetone, followed by distilled water and dried. Water contact angles on the surfaces were measured by a sessile drop method using an optical contact angle measuring system (Data Physics OCA15EC, Filderstadt, Germany). Distilled water droplets of volume $5 \mu \mathrm{L}$ were placed on the surfaces. Images of water droplets 
were taken in directions perpendicular and parallel to the direction of MG, as shown in Figure 3a. Ten measurements of water contact angles were taken in both the perpendicular direction $\left(\theta_{\perp}\right)$ and parallel direction $\left(\theta_{\Pi}\right)$. Average values of the contact angles are reported $\left(\right.$ error $\pm 2^{\circ}$ ).

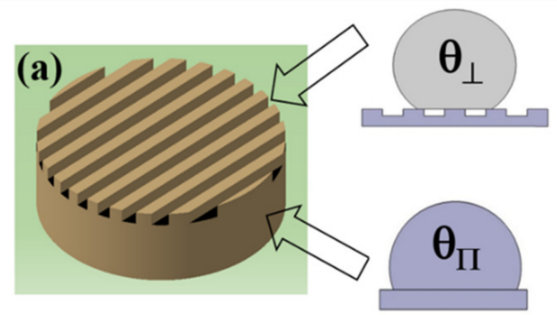

(b) Flat $77.7^{\circ}$

(c) MG1

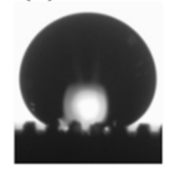

$\theta_{\perp} 137.6^{\circ}$

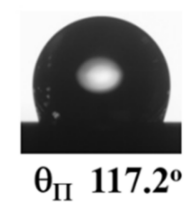

(e) MG3

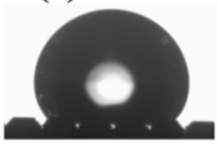

$\theta_{\perp} 121^{\circ}$

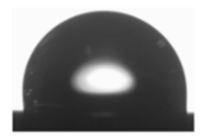

$\theta_{\Pi} \mathbf{1 0 2}^{\circ}$

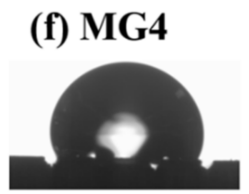

$\theta_{\perp} \mathbf{1 1 3 . 2}^{\circ}$

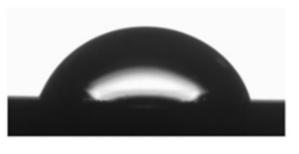

(d) MG2

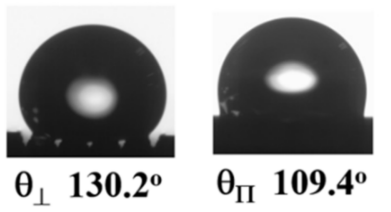

Figure 3. (a) Directions of water contact angle measurement on MG: perpendicular $\left(\theta_{\perp}\right)$ and parallel $\left(\theta_{\Pi}\right)$ to the direction of MG. Images of water droplets on surfaces, prior to their long-term exposure to $3.5 \mathrm{wt}$. \% NaCl solution: (b) flat surface and (c-f) MG.

\subsection{Electrochemical Corrosion Test}

Potentiodynamic polarization tests were conducted for the surfaces at room temperature $\left(27^{\circ} \mathrm{C}\right)$ in saline water $(3.5 \mathrm{wt} . \% \mathrm{NaCl}$ solution), using an electrochemical work station (Autolab, Metrohm, The Netherlands). The SS304's flat surface and MG were taken as the working electrode, $\mathrm{Ag} / \mathrm{AgCl}$ as the reference electrode and platinum as the counter electrode. The area of the surfaces exposed to the corrosive fluid was $1 \mathrm{~cm}^{2}$. Prior to the corrosion test, the surfaces were immersed in $3.5 \mathrm{wt}$. \% NaCl solution for $60 \mathrm{~min}$ to obtain steady state open circuit potential. For each surface, the potential range selected for the test was $\pm 0.1 \mathrm{~V}$ relative to its open circuit potential. Potentiodynamic polarization curves were generated at the scan rate of $1 \mathrm{mV} / \mathrm{s}$. From the linear polarization resistance curves, corrosion potential ( $\left.\mathrm{E}_{\text {corr }}\right)$ and corrosion current density $\left(\mathrm{i}_{\text {corr }}\right)$ were determined. Corrosion rate was estimated using the Stern-Geary relation [21]. Surfaces after corrosion test were examined using a field-emission scanning electron microscope (FEI-Quanta-FEG 250, Hillsboro, OR, USA).

\subsection{Long-Term Exposures to Saline Water}

To evaluate the corrosion behaviour of surfaces over long-term duration, the surfaces were exposed to saline water ( $3.5 \mathrm{wt}$. \% NaCl solution), under two different conditions: (i) intermittent exposure by drop method for $168 \mathrm{~h}$ and (ii) continuous exposure by dip method for $168 \mathrm{~h}$. In the intermittent exposure test, using a droplet generator, saline water droplets at the rate of one droplet per second were dropped on the surfaces that were kept inclined at $45^{\circ}$. This method is used in industrial weathering tests [22]. Static water contact angles $\left(\theta_{\perp}, \theta_{\Pi}\right)$ were measured at an interval of every $24 \mathrm{~h}$ of intermittent exposure, until $168 \mathrm{~h}$. In the continuous exposure test, the surfaces were dipped in saline water for $168 \mathrm{~h}$, and static water contact angles $\left(\theta_{\perp}, \theta_{\Pi}\right)$ were measured at an interval of every $24 \mathrm{~h}$ of continuous exposure, until $168 \mathrm{~h}$. After an interval of every $24 \mathrm{~h}$, prior to measuring the 
contact angles, the surfaces were dried in open atmospheric conditions for $30 \mathrm{~min}$. After the long-term exposures, i.e., after intermittent exposure for $168 \mathrm{~h}$ and after continuous exposure for $168 \mathrm{~h}$, corrosion test was conducted for the surfaces as described in Section 2.3.

\section{Results and Discussion}

\subsection{Wetting Behaviour}

Wettability of a surface is characterised by the contact angle a water droplet makes on its surface. Measured contact angles (CA) prior to long-term exposures of MG as a function of their width ratio $\left(\mathrm{WR}=\mathrm{W}_{\mathrm{r}} / \mathrm{W}_{\mathrm{g}}\right.$ ) are shown in Figure 4 . The flat surface is hydrophilic with $\theta \approx 77.7^{\circ}$ and $M G$ are hydrophobic $\left(\theta_{\perp}\right.$ and $\left.\theta_{\Pi}>90^{\circ}\right)$. CA values decrease with the increase in the width ratio. WR of MG is $>1$. Hence, the increase in WR value corresponds to the increase in the ridge width $\left(\mathrm{W}_{\mathrm{r}}\right)$, as the groove width $\left(\mathrm{W}_{\mathrm{g}}\right)$ is constant. CA of the surfaces measured before, during and after intermittent and continuous exposures to $\mathrm{NaCl}$ solution as a function of the exposure time ( $t$ ) are shown in Figure 5. CA values of surfaces decrease with the increase in the exposure time. The decrease is very noticeable for the flat surface when compared to those of MG. Defining $\theta_{\mathrm{r}}$ as the magnitude of reduction in $\mathrm{CA}$ due to long-term exposures (i.e., $\theta_{\mathrm{r}}=\mathrm{CA}$ before long-term exposure $-\mathrm{CA}$ after long-term exposure), it is seen that $\theta_{\mathrm{r}}$ values of MG are lower than those of the flat surface (Table 2). Wettability of the flat surface increases rapidly upon long-term exposures than those of MG.

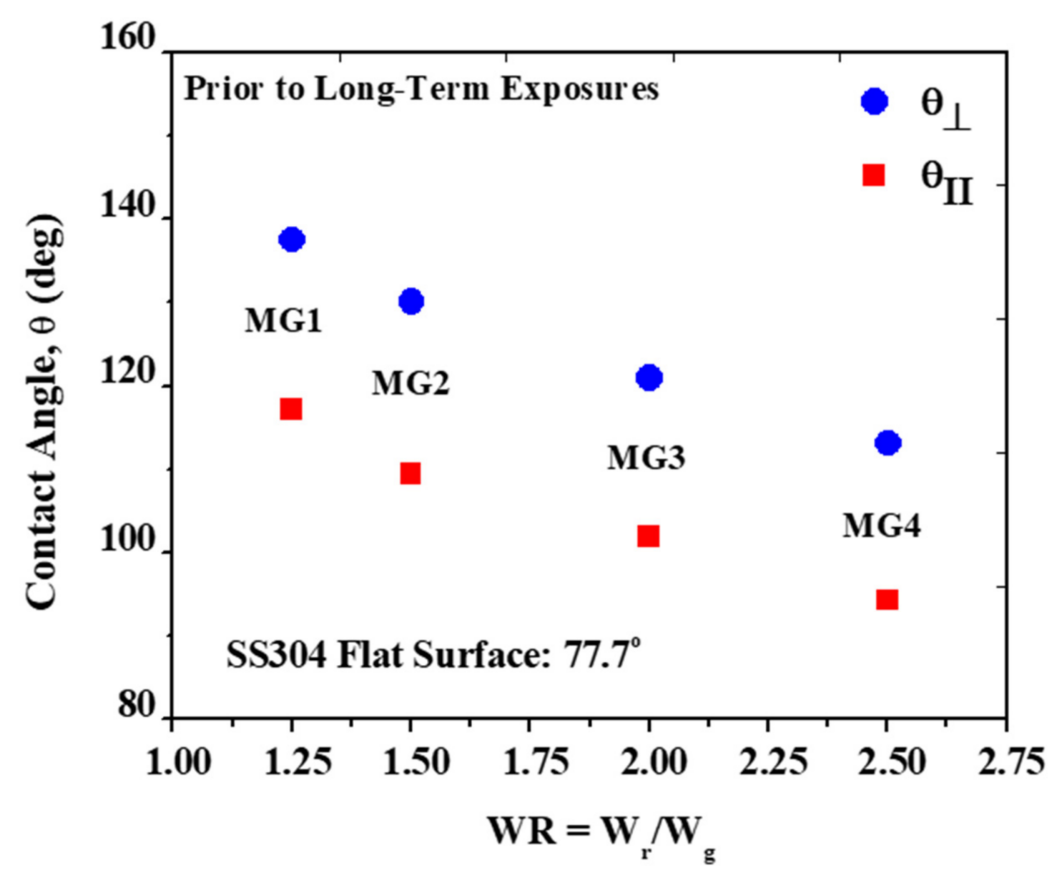

Figure 4. Contact angles of $\mathrm{MG}\left(\theta_{\perp}, \theta_{\Pi}\right)$, prior to their long-term exposures to $3.5 \mathrm{wt}$. $\% \mathrm{NaCl}$ solution, as a function of their width ratio $\left(\mathrm{WR}=\mathrm{W}_{\mathrm{r}} / \mathrm{W}_{\mathrm{g}}\right)$.

Table 2. Contact angle of surfaces prior to long-term exposures to $3.5 \mathrm{wt}$. $\% \mathrm{NaCl}$ solution. $\theta_{\mathrm{r}}$ values $\left(\theta_{\mathrm{r}}=\mathrm{CA}\right.$ before long-term exposure - CA after long-term exposure) of surfaces: (I) after intermittent exposure and (II) after continuous exposure.

\begin{tabular}{|c|c|c|c|c|c|c|c|}
\hline \multirow{3}{*}{ Surface } & \multirow{3}{*}{$\begin{array}{l}\text { Width Ratio } \\
\text { WR }=W_{\mathbf{r}} / W_{g}\end{array}$} & \multirow{2}{*}{\multicolumn{2}{|c|}{$\begin{array}{l}\text { Contact Angle }\left({ }^{\circ}\right) \text { Prior to } \\
\text { Long-Term Exposures }\end{array}$}} & \multicolumn{4}{|c|}{$\theta_{\mathrm{r}}\left({ }^{\circ}\right)$} \\
\hline & & & & \multicolumn{2}{|c|}{ I } & \multicolumn{2}{|c|}{ II } \\
\hline & & $\theta_{\perp}$ & $\theta_{\Pi}$ & $\Delta \theta_{\perp}$ & $\Delta \theta_{\Pi}$ & $\Delta \theta_{\perp}$ & $\Delta \theta_{\Pi}$ \\
\hline Flat & & \multicolumn{2}{|c|}{77.7} & \multicolumn{2}{|c|}{8.6} & \multicolumn{2}{|c|}{9.5} \\
\hline MG1 & 1.25 & 137.6 & 117.2 & 2.2 & 2.1 & 4.1 & 4.0 \\
\hline MG2 & 1.50 & 130.2 & 109.4 & 2.4 & 2.2 & 4.4 & 4.7 \\
\hline MG3 & 2.00 & 121.0 & 102.0 & 2.5 & 2.5 & 4.9 & 5.0 \\
\hline MG4 & 2.50 & 113.2 & 94.3 & 2.6 & 3.5 & 5.1 & 5.2 \\
\hline
\end{tabular}



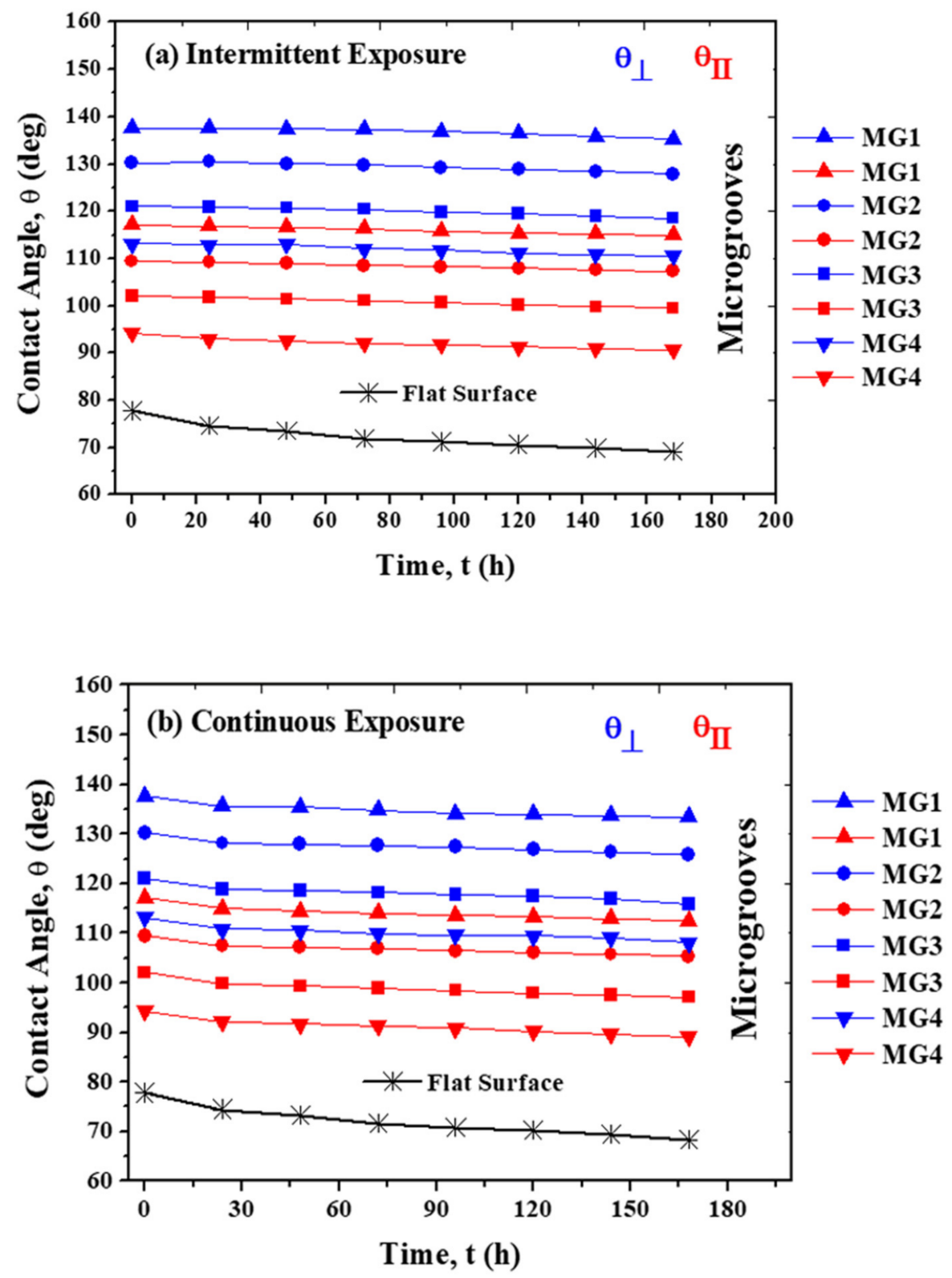

Figure 5. Contact angles of the surfaces measured (a) before $(0 \mathrm{~h})$, during and after intermittent exposure and $(\mathbf{b})$ before $(0 \mathrm{~h})$, during and after continuous exposure to $3.5 \mathrm{wt}$. $\% \mathrm{NaCl}$ solution for $168 \mathrm{~h}$ as a function of exposure time $(\mathrm{t})$.

Anisotropic wetting is a characteristic of unidirectional surface topographies. Due to their anisotropic topography, MG have CA values, such that their $\theta_{\perp}>\theta_{\Pi}$. Water droplets tend to spread along the groove direction as the energy barrier for spreading is lower than that in the direction across the grooves, giving rise to wetting anisotropy [23]. Anisotropic angle, $\theta_{\mathrm{a}}\left(\theta_{\mathrm{a}}=\theta_{\perp}-\theta_{\Pi}\right)$, is an indicator of directional wettability of unidirectional anisotropic surfaces. $\theta_{\mathrm{a}}$ depends on groove width and groove depth $[15,24]$. MG have the same groove width $(200 \mu \mathrm{m})$ and same groove depth $(100 \mu \mathrm{m})$. Hence, their $\theta_{\mathrm{a}}$ values are same $\approx 18^{\circ} \pm 1^{\circ} . \theta_{\mathrm{a}}$ is zero for the flat surface, which means a water droplet spreads on its surface uniformly in all directions.

Wetting of topographically modified surfaces occurs in two distinct states, namely: (a) Wenzel state, wherein water droplets completely wet their surface features and (b) Cassie-Baxter state, wherein water droplets wet the top of their surface features, with air trapped in between their surface features, beneath the water droplets (composite wetting, i.e., solid-liquid-air interface) [23]. As seen from Figure 3, the wetting of MG is in 
the Cassie-Baxter state $\left(\theta_{\mathrm{CB}}\right)$. According to the Cassie-Baxter model, CA of a surface is dependent on $\mathrm{f}$, the solid fraction ( $\mathrm{f}=$ actual surface area/planar surface area) of the surface (Equation (1), [24]).

$$
\operatorname{Cos} \theta_{\mathrm{CB}}=\mathrm{f}\left(\operatorname{Cos} \theta_{0}+1\right)-1
$$

where, $\theta_{\text {Св }}$ is the CA in Cassie-Baxter state, $\mathrm{f}$ is the solid fraction and $\theta_{0}$ is the CA of flat surface. For $M G$, the solid fraction was estimated as $W_{r} /\left(W_{r}+W_{g}\right)$. Solid fraction values of MG are: $0.55,0.60,0.66$ and 0.71 for MG1, MG2, MG3 and MG4, respectively. $f=1$ for the flat surface.

The solid fraction parameter is the surface area available for wetting by water droplets. Therefore, it is seen that CA of MG decreases with the increase in their width ratio $\left(\mathrm{WR}=\mathrm{W}_{\mathrm{r}} / \mathrm{W}_{\mathrm{g}}\right)$, in particular with the increase in their ridge width $\left(\mathrm{W}_{\mathrm{r}}\right)$, as their groove width $\left(W_{\mathrm{g}}\right)$ is constant. Decrease in $W_{\mathrm{r}}$ corresponds to decrease in the surface area available for wetting, which in turn increases the CA $\left(\theta_{\perp}, \theta_{\Pi}\right)$. Hence, amongst the microgrooves, MG1 that has the smallest WR of 1.25 and smallest $f$ value of 0.55 has the highest CA values $\left(\theta_{\perp} 137.6^{\circ}\right.$ and $\theta_{\Pi} 117.2^{\circ}$ before long-term exposures; $\theta_{\perp} 135.4^{\circ}$ and $\theta_{\Pi} 115.1^{\circ}$ after intermittent exposure; $\theta_{\perp} 133.5^{\circ}$ and $\theta_{\Pi} 113.2^{\circ}$ after continuous exposure). MG4 that has the largest WR of 2.5 and largest $f$ value of 0.71 , amongst the microgrooves, has the lowest $C A$ values $\left(\theta_{\perp} 113.2^{\circ}\right.$ and $\theta_{\Pi} 94.3^{\circ}$ before long-term exposures; $\theta_{\perp} 110.6^{\circ}$ and $\theta_{\Pi} 90.8^{\circ}$ after intermittent exposure; $\theta_{\perp} 108.1^{\circ}$ and $\theta_{\Pi} 89.1^{\circ}$ after continuous exposure). The flat surface has $\mathrm{f}=1$, and has the lowest CA values of all the surfaces $\left(77.7^{\circ}\right.$ before long-term exposures; $69.1^{\circ}$ after intermittent exposure; $68.2^{\circ}$ after continuous exposure). Wetting of a surface by a fluid directly depends on the area exposed by the surface to the fluid, i.e., the area of the surface that comes in contact with the fluid. Considering $\theta_{\mathrm{r}}$ values of surfaces (Table 2), the hydrophobic MG have antiwetting ability over long-term exposures, as indicated by their lower $\theta_{\mathrm{r}}$ values. In contrast, the hydrophilic flat surface is prone to severe wetting over long-term exposures, as indicated by its higher $\theta_{\mathrm{r}}$ values.

\subsection{Corrosion Behaviour}

Corrosion potential $\left(\mathrm{E}_{\mathrm{corr}}\right)$, corrosion current density $\left(\mathrm{i}_{\mathrm{corr}}\right)$ and corrosion rate $(\mathrm{CR})$ of the surfaces before long-term exposures are listed in Table 3. Their values after long-term exposures are listed in Table 4. Tafel plots of the flat surface and MG1 are shown in Figure 6. From Tables 3 and 4, it is seen that when compared to the flat surface, MG have (i) higher

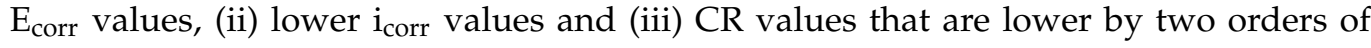
magnitude.

Table 3. Corrosion potential ( $\left.\mathrm{E}_{\mathrm{corr}}\right)$, corrosion current density ( $\left.\mathrm{i}_{\mathrm{corr}}\right)$ and corrosion rate (CR) of surfaces, prior to long-term exposures to $3.5 \mathrm{wt}$. \% $\mathrm{NaCl}$ solution.

\begin{tabular}{cccc}
\hline & \multicolumn{3}{c}{ Prior to Long-Term Exposures } \\
\cline { 2 - 4 } Surface & $\begin{array}{c}\mathbf{E}_{\mathbf{c o r r}} \\
\mathbf{( V )}\end{array}$ & $\begin{array}{c}\mathbf{i}_{\text {corr }} \\
\left(\mathbf{A} / \mathbf{c m}^{2}\right)\end{array}$ & $\begin{array}{c}\mathbf{C R} \times \mathbf{1 0}^{-\mathbf{4}} \\
(\mathbf{m m} / \mathbf{y e a r})\end{array}$ \\
\hline Flat Surface & -0.5121 & $11.16 \times 10^{-6}$ & 166 \\
MG1 & -0.0374 & $2.10 \times 10^{-8}$ & 1.7 \\
MG2 & -0.0451 & $2.46 \times 10^{-8}$ & 2.1 \\
MG3 & -0.1078 & $2.65 \times 10^{-8}$ & 2.4 \\
MG4 & -0.1165 & $2.85 \times 10^{-8}$ & 2.9 \\
\hline
\end{tabular}


Table 4. Corrosion potential ( $\left.\mathrm{E}_{\mathrm{corr}}\right)$, corrosion current density $\left(\mathrm{i}_{\mathrm{corr}}\right)$ and corrosion rate of surfaces, after long-term exposures to 3.5 wt. \% NaCl solution.

\begin{tabular}{|c|c|c|c|c|c|c|}
\hline \multirow[b]{2}{*}{ Surface } & \multicolumn{3}{|c|}{ After Intermittent Exposure } & \multicolumn{3}{|c|}{ After Continuous Exposure } \\
\hline & $\begin{array}{l}E_{\text {corr }} \\
\text { (V) }\end{array}$ & $\begin{array}{c}\mathbf{i}_{\text {corr }} \\
\left(\mathrm{A} / \mathrm{cm}^{2}\right)\end{array}$ & $\begin{array}{l}\mathrm{CR} \times 10^{-4} \\
(\mathrm{~mm} / \text { year })\end{array}$ & $\begin{array}{l}E_{\text {corr }} \\
\text { (V) }\end{array}$ & $\begin{array}{c}\mathbf{i}_{\text {corr }} \\
\left(\mathrm{A} / \mathrm{cm}^{2}\right)\end{array}$ & $\begin{array}{l}\mathrm{CR} \times 10^{-4} \\
(\mathrm{~mm} / \text { year })\end{array}$ \\
\hline Flat & -0.2703 & $26.60 \times 10^{-6}$ & 311 & -0.2789 & $26.90 \times 10^{-6}$ & 313 \\
\hline MG1 & -0.0454 & $2.12 \times 10^{-8}$ & 2.2 & -0.0639 & $2.18 \times 10^{-8}$ & 2.7 \\
\hline MG2 & -0.0766 & $2.58 \times 10^{-8}$ & 2.5 & -0.0889 & $2.66 \times 10^{-8}$ & 3.0 \\
\hline MG3 & -0.1174 & $2.87 \times 10^{-8}$ & 2.7 & -0.1202 & $2.92 \times 10^{-8}$ & 3.1 \\
\hline MG4 & -0.1789 & $3.16 \times 10^{-8}$ & 3.2 & -0.1834 & $3.23 \times 10^{-8}$ & 3.7 \\
\hline
\end{tabular}

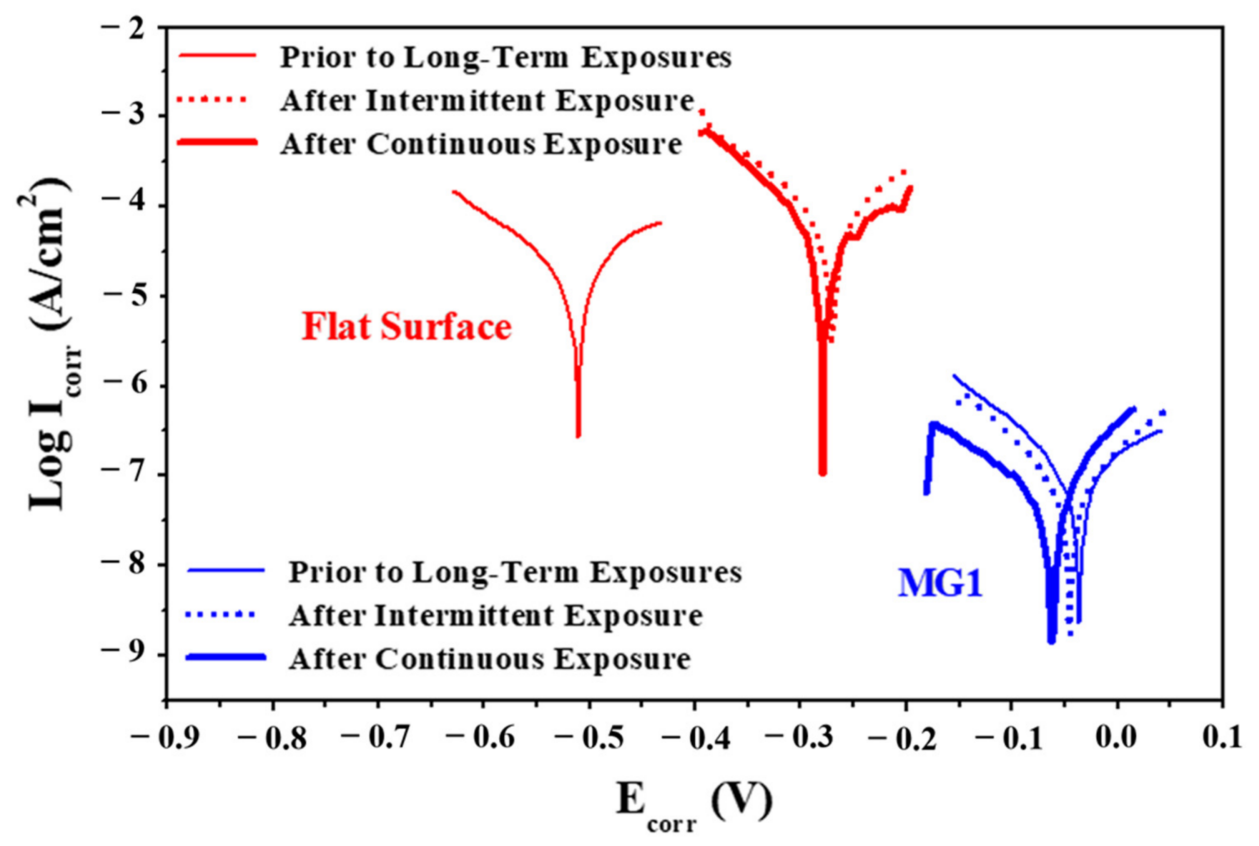

Figure 6. Tafel plots of the flat surface and MG1, prior to long-term exposures, after intermittent exposure and after continuous exposure, to $3.5 \mathrm{wt}$. \% $\mathrm{NaCl}$ solution.

$\mathrm{CR}$ values of $M G$, before and after long-term exposures as a function of their width ratio (WR), are plotted in Figure 7. Their CR value increases with the increase in WR, and in magnitude it is in the order: after continuous exposure > after intermittent exposure > prior to long-term exposures.

As seen from Figures 4, 5 and 7, with the increase in WR, CA values decrease, whereas $C R$ values increase for MG. Therefore, $C R$ decreases with the increase in CA (i.e., decrease in $\mathrm{f}$, the solid fraction), indicating that surface wettability determines the corrosion rate. Wettability of a surface depends on the area available for wetting (i.e., $f$, the solid fraction value) by corrosive fluid. Hence, amongst the microgrooves, MG1 that has the highest $C A$ values has the lowest $C R$ at all the test conditions, and vice versa. Amongst all the surfaces, the flat surface has the lowest $\mathrm{CA}$ and hence has the highest $\mathrm{CR}$ at all the test conditions. On a comparative note, for the flat surface, CA reduced by $11 \%$ and $12.2 \%$ upon intermittent and continuous exposures, respectively and correspondingly its $\mathrm{CR}$ value increased by $87.3 \%$ and $88.5 \%$ with respect to its $C R$ value prior to its long-term exposures. In contrast, for MG1, CA $\left(\theta_{\perp}, \theta_{\Pi}\right)$ reduced by $1.59 \%, 1.79 \%$ and $2.9 \%, 3.4 \%$ upon intermittent and continuous exposures, respectively, and correspondingly its $\mathrm{CR}$ increased by $29.4 \%$.and $58.82 \%$ with respect to its $C R$ value prior to its long-term exposure. As observed in the present work, the dependence of CR on CA such that the pattern with highest $C A$ has lowest $C R$ has been reported earlier for other metallic patterns $[6,7,9,11]$. 


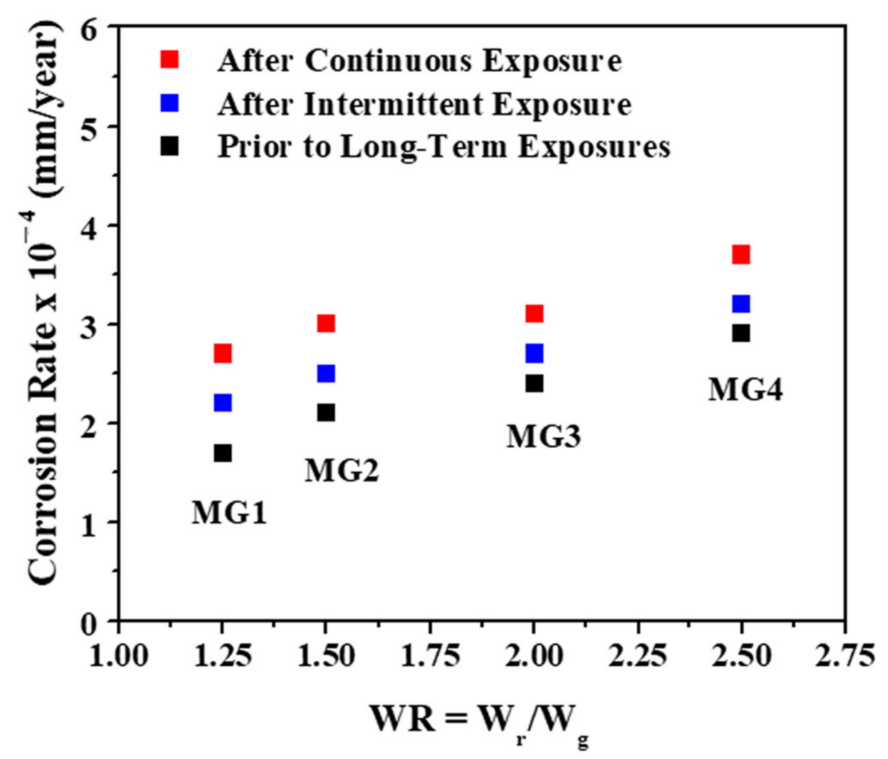

Figure 7. Corrosion rate of MG before and after long-term exposures to $3.5 \mathrm{wt}$. \% $\mathrm{NaCl}$ solution as a function of their width ratio $\left(\mathrm{WR}=\mathrm{W}_{\mathrm{r}} / \mathrm{W}_{\mathrm{g}}\right)$. Corrosion rate of the flat surface (mm/year) is $166 \times 10^{-4}$ prior to long-term exposures, is $311 \times 10^{-4}$ after intermittent exposure and is $313 \times 10^{-4}$ after continuous exposure to $\mathrm{NaCl}$ solution.

Corrosion of SS304 occurs by pitting in $\mathrm{NaCl}$ solution [25]. Although passive film forms on the steel surface, it is prone to localized breakdown in the presence of aggressive chloride ions and causes pitting [25]. Chloride ions penetrate and move through passive film, and eventually as they reach metal/film interface they cause film breakdown and the film gets detached from surface $[25,26]$. In the absence of passive film, the new surface becomes exposed from underneath, which accelerates corrosion. Also, pitting corrosion accelerates due to its autocatalytic nature [27].

In the present work, the flat surface exposes its entire surface area to the corrosive fluid (Figure 8) and so experiences severe corrosion, whereas in the case of MG, the corrosive fluid wets and corrodes only the top of their ridges, due to their composite wetting [28-30] (Figure 8). Air trapped in their grooves resists the entry of the corrosive fluid and prevents electrochemical activity $[6,7,9,10]$.

(a)

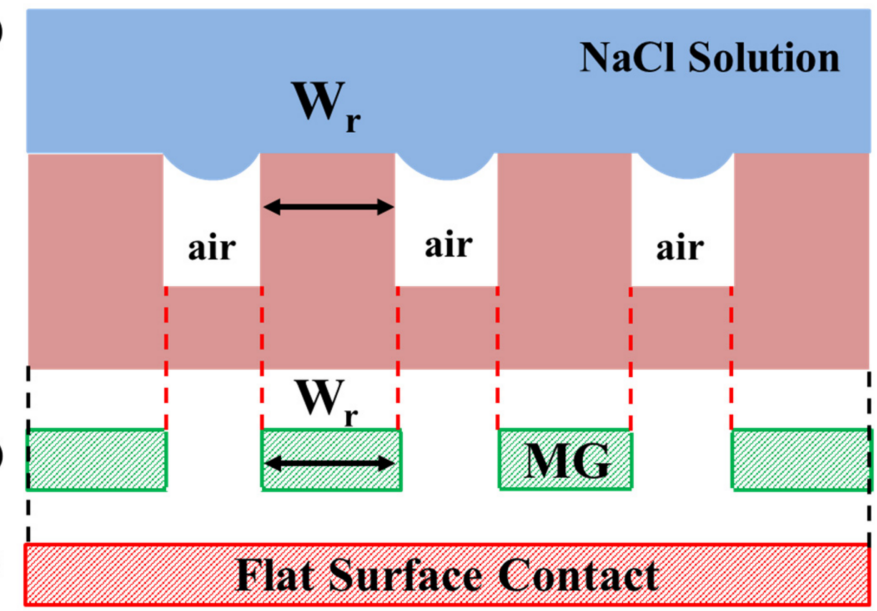

Figure 8. (a) Schematic showing wetting of $\mathrm{MG}$ with the corrosive fluid ( $\mathrm{NaCl}$ solution), wherein the fluid wets the top of their ridges, with air trapped in their grooves (composite wetting, i.e., solid-liquid-air interface). (b) Area wetted by the fluid on MG (green shaded areas). (c) Area wetted by the fluid on the flat surface (red shaded area). 
Figure 9 shows corrosion pits on the flat surface and MG1 after corrosion test. These are metastable pits that usually form at low potentials [31]. In stainless steels, during the early stage of corrosion, chloride ions damage the passive film and promote the nucleation of metastable pits [31]. Stainless steels repassivate upon metastable pit formation [31,32]. With increase in potential, eventually, stable pits form that break down the passive film. The potential at which stable pits form is higher than the passivation potential [33]. Usually, stable pits are larger in size (e.g., $50 \mu \mathrm{m}$ diameter; seen on 304L austenitic steel in 3.5\% $\mathrm{NaCl}$ [25]) than metastable pits [31-33]. Reports [7,9] mention that the pitting potential ( $E_{\text {pit }}$, the potential above which stable pits form) was higher for the metallic patterns than their flat counterpart surfaces and that the pattern with the highest CA showed the highest $\mathrm{E}_{\text {pit value [7]. }}$
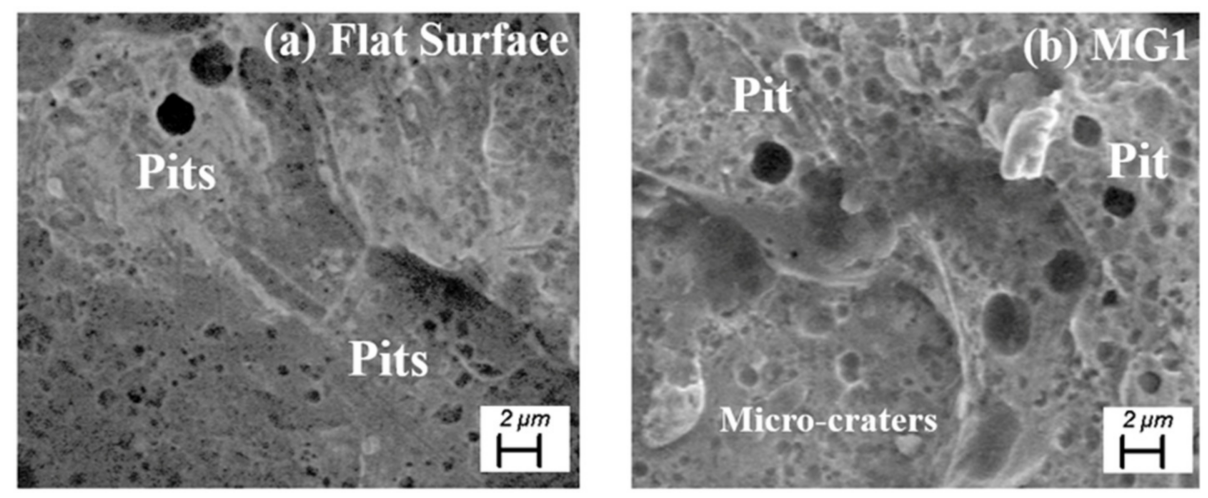

Figure 9. Representative SEM images of (a) flat surface and (b) MG1 surface taken after corrosion test (after continuous exposure to 3.5 wt. \% $\mathrm{NaCl}$ solution).

Reduction in CA values of surfaces due to long-term exposures to $\mathrm{NaCl}$ solution (Table 2) could be attributed to the occurrence of pitting on their surfaces. Corrosion pits are holes that are relatively small in size [25,27] and can actively sustain capillarity [34]. Hence, formation of corrosion pits on surfaces during their long-term exposures to $\mathrm{NaCl}$ solution increases their surface wettability causing a reduction in their CA values and as a consequence their CR values increase (Figure 7). Therefore, it is observed that their CA values are in the order: after continuous exposure < after intermittent exposure < prior to long-term exposures to $\mathrm{NaCl}$ solution, and their $\mathrm{CR}$ values are in the order: after continuous exposure $>$ after intermittent exposure $>$ prior to long-term exposures to $\mathrm{NaCl}$ solution.

Corrosion inhibition efficiency $(\eta)$ of MG was estimated by using Equation (2) [35].

$$
\eta(\%)=\left[\left(\mathrm{i}_{\text {corr (f) }}-\mathrm{i}_{\operatorname{corr}(\mathrm{MG})}\right) / \mathrm{i}_{\operatorname{corr}(\mathrm{f})}\right] \times 100
$$

where, $i_{\text {corr (f) }}$ is the current density of the flat surface and $i_{\text {corr (MG) }}$ is that of a MG. $\eta$ values of MG before and after long-term exposures to $\mathrm{NaCl}$ solution are listed in Table 5. MG are efficient in inhibiting saline water corrosion over the long-time duration with $\eta$ values $\geq 88 \%$.

Table 5. Corrosion inhibition efficiency ( $\eta$ ) of MG (Equation (2)).

\begin{tabular}{|c|c|c|c|}
\hline \multirow[b]{2}{*}{ Surface } & \multicolumn{3}{|c|}{ Corrosion Inhibition Efficiency $(\eta), \%$} \\
\hline & $\begin{array}{c}\text { Prior to } \\
\text { Long-Term Exposures }\end{array}$ & $\begin{array}{l}\text { After Intermittent } \\
\text { Exposure }\end{array}$ & $\begin{array}{c}\text { After Continuous } \\
\text { Exposure }\end{array}$ \\
\hline MG1 & 81 & 92 & 93 \\
\hline MG2 & 78 & 90 & 90 \\
\hline MG3 & 76 & 89 & 89 \\
\hline MG4 & 75 & 88 & 88 \\
\hline
\end{tabular}




\subsection{Factors Influencing Wetting and Corrosion Behaviour of Microgrooves}

For hydrophobic micropatterns that follow the Cassie-Baxter model, the solid fraction (f) influences their surface wetting and consequently determines their corrosion. Along with the solid fraction, the surface roughness on their ridges also influences their surface wetting and corrosion rate. To elucidate this fact, results from a previous work on SS304 microgrooves (GS) with width ratio (WR) $<1[6]$ and the results from the present work on MG (WR > 1), are compared. $W_{r}, W_{g}, W R$ and solid fraction (f) values of GS are given in Table 6 [6]. Optical profilometer images of GS-1 and MG1 are shown in Figure 10. GS have the same groove depth $(\mathrm{Dg} \approx 58 \mu \mathrm{m})$, almost similar groove width $\left(\mathrm{W}_{\mathrm{g}} \approx 140 \mu \mathrm{m}\right.$, $-2 /+1 \mu \mathrm{m})$, but varying ridge width $\left(\mathrm{W}_{\mathrm{r}}\right)[6]$.

Table 6. Nomenclature, geometrical parameters, width ratio, water contact angles and f values (Cassie-Baxter Equation (1)) of SS304 microgrooves with WR $<1$. (data from [6]).

\begin{tabular}{|c|c|c|c|c|c|c|}
\hline \multirow{2}{*}{ Surface } & \multirow{2}{*}{$\begin{array}{l}\text { Ridge Width } \\
\left(\mathrm{W}_{\mathrm{r}}\right)(\mu \mathrm{m})\end{array}$} & \multirow{2}{*}{$\begin{array}{l}\text { Groove Width } \\
\qquad\left(W_{g}\right)(\mu \mathrm{m})\end{array}$} & \multirow{2}{*}{$\begin{array}{l}\text { Width Ratio } \\
W R=W_{r} / W_{g}\end{array}$} & \multicolumn{2}{|c|}{ Contact Angle $\left(^{\circ}\right)$} & \multirow{2}{*}{ f } \\
\hline & & & & $\theta_{\perp}$ & $\theta_{\Pi}$ & \\
\hline Flat & & & \multicolumn{4}{|c|}{77.7} \\
\hline GS-1 & 55.70 & 138.50 & 0.40 & 139.6 & 111.2 & 0.28 \\
\hline GS-2 & 111.53 & 140.61 & 0.79 & 133.8 & 108.9 & 0.44 \\
\hline GS-3 & 118.27 & 141.76 & 0.83 & 133.2 & 107.0 & 0.46 \\
\hline
\end{tabular}
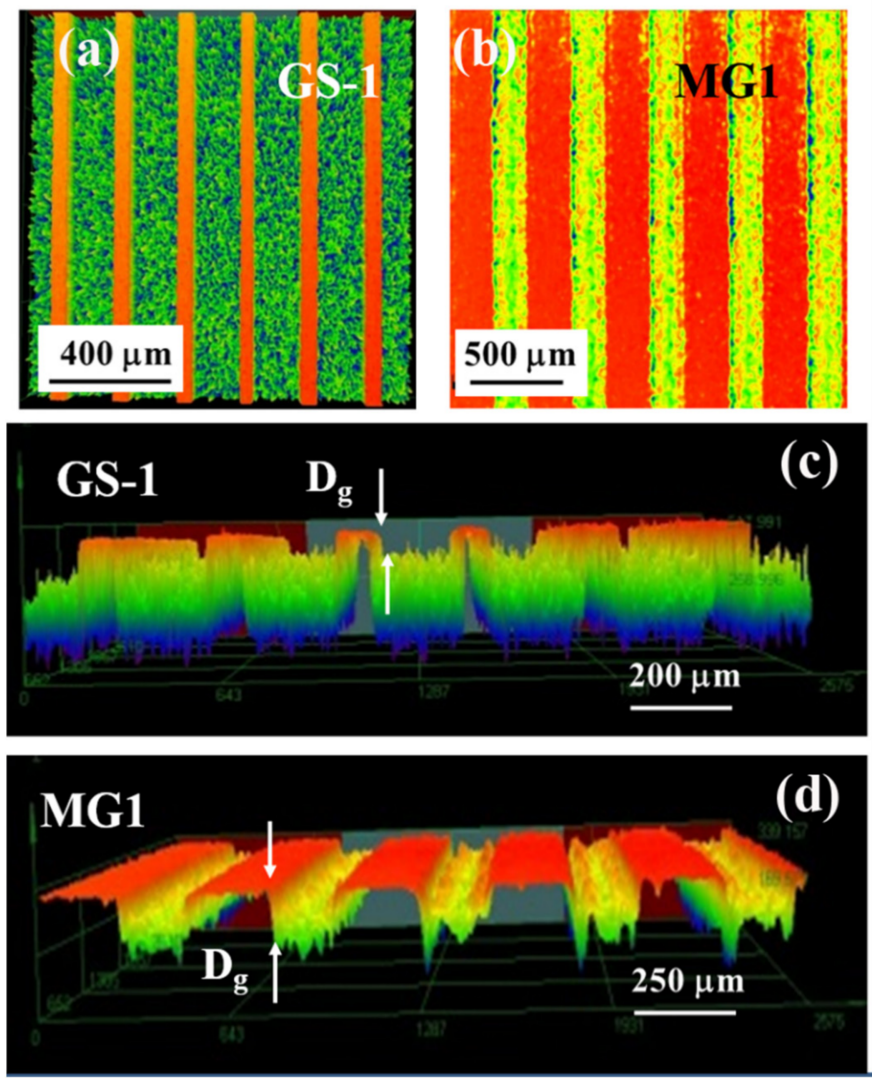

Figure 10. Optical profilometry images of (a) GS-1 top view, (b) MG1 top view, (c) GS-1 side view and (d) MG1 side view. $D_{g}$ is the groove depth. $D_{g}$ of GS-1 is $58 \mu \mathrm{m}$ (data from [6]) and that of MG1 is $100 \mu \mathrm{m}$ (present work).

CA $\left(\theta_{\perp}, \theta_{\Pi}\right)$ and CR of GS and MG as a function of their width ratio $\left(W R=W_{r} / W_{g}\right)$ are shown in Figure 11. Solid fraction (f) values of GS and MG are mentioned near their respective CR data points. MG have larger $\mathrm{f}$ values when compared to those of GS. Hence, it could be expected for MG to have (i) lower CA values than those of GS (blue arrow: 
expected decreasing trend of $\theta_{\perp}$ values of MG compared to those of GS; red arrow: expected decreasing trend of $\theta_{\Pi}$ values of MG compared to those of GS) and (ii) higher CR values than those of GS (black arrow: expected increasing trend of CR values of MG compared to those of GS). However, the CA values and CR values of MG do not follow the expected trends; rather, the measured CA values are higher and the measured $C R$ values are lower than their respective expected trends, as can be seen from Figure 11. The discrepancy between the expected trends and the measured values of CA and CR of MG is due to the higher surface roughness of MG on their ridges. Average surface roughness on the ridges of MG is $4.85 \mu \mathrm{m}$, which is two orders higher than the roughness value on the ridges of GS $(0.013 \mu \mathrm{m},[6])$. GS were fabricated by a chemical etching process [6], whereas MG were fabricated by WEDM. Micro-craters form on MG ridge surfaces (Figure 2c), due to electric sparks during the electrical discharge machining process, which gives rise to higher surface roughness $[20,36,37]$. It should be noted here that the theoretical estimation of the solid fraction (f) of the microgrooves includes ridge width $\left(\mathrm{W}_{\mathrm{r}}\right)$ and not the surface roughness on their ridges. Hence, although the solid fraction values of MG are higher than those of GS according to the theoretical estimates, it is reasonable to suggest that the solid fraction values of MG are overestimated, as the surface roughness is not taken into account. Rougher surfaces increase CA and reduce wettability, which in turn reduces corrosion [38-40]. Also, groove depth $\left(\mathrm{D}_{\mathrm{g}}\right)$ influences $C A$ values, such that taller grooves often demonstrate increased contact angles [14]. $\mathrm{D}_{\mathrm{g}}$ of GS is $58 \mu \mathrm{m}$ [6], whereas that of MG is $100 \mu \mathrm{m}$ (Figure 10). Thus, the taller grooves and rougher ridge surfaces of MG further enhance their CA values and reduce their wettability, which contributes towards lowering their CR values (Figure 11). In other words, if MG had the same $D_{g}$ and same surface roughness on their ridges as those of GS, their CA values would have been lower and thereby their $\mathrm{CR}$ values would have been higher than those observed in the present work, owing to their larger solid fraction (f) values than those of GS. It is notable that amongst MG, the CA and CR depend on their solid fraction. Similarly, amongst GS microgrooves, the $\mathrm{CA}$ and $\mathrm{CR}$ depend on their solid fraction [6].

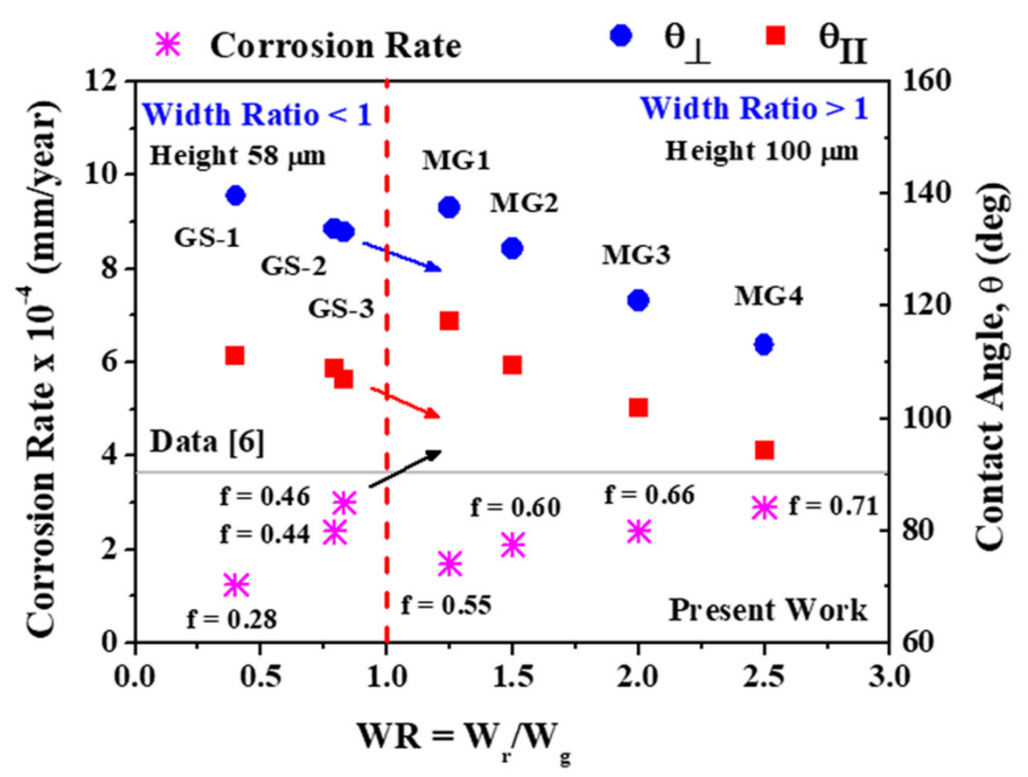

Figure 11. Water contact angles $\left(\theta_{\perp}, \theta_{\Pi}\right)$ and corrosion rate of GS microgrooves $(\mathrm{WR}<1)$ (data from [6]) and MG (WR > 1, present work, prior to long-term exposures to $3.5 \mathrm{wt}$. \% $\mathrm{NaCl}$ solution). Solid fraction (f) of the GS and MG are mentioned near their respective corrosion rate data points.

The above discussion highlights that solid fraction (f), surface roughness of ridges and groove depth $\left(D_{g}\right)$ together determine the wettability of patterned surfaces (consequently their corrosion). Note that, natural antiwetting surfaces are very effective due to the combination of these features. As an example, rice leaves have taller microgrooves (height 
$200 \mu \mathrm{m})$, thinner ridge width $(50 \mu \mathrm{m})$ and have micro-papilla (height 3-5 $\mu \mathrm{m}$, width 5-8 $\mu \mathrm{m})$ on their ridges that provide roughness and enhance water-repellence [41]. The roughness effect on the antiwetting characteristic becomes amplified as ridges become thinner. MG1 that has the smallest $W_{r}$ amongst the MG thus has the highest $C A$, and thereby experiences the lowest CR.

\subsection{Advantages of Topographical Modification}

The prime advantage of topographical modification is the flexibility in designing micropatterns due to their geometrical nature. Other notable advantages are:

- Absence of complex chemistry and interface in micropatterns. Chemical modification approaches such as coatings, platings and paints create a chemical barrier on surfaces that prevent corrosive fluids from contacting metallic surfaces. In the topographical modification approach, fluids are in contact with metallic surfaces, but the area of contact of surfaces with fluids is greatly reduced. Although chemical modification approaches effectively reduce corrosion, they have several critical issues that can cause loss of anticorrosion performance. These issues need to be considered while formulating the main functionality of protection against corrosion, such as adhesion to surfaces due to the presence of interface, layer thickness, mechanical durability, presence of micro-defects and chemical complexity in coatings [42-44]; non-uniform thickness, brittleness and cracking in plating [45]; the presence of volatile organic compounds in paints [44]; and most inhibitors are hazardous and expensive [46]. Micropatterns are environmentally friendly and can be implemented over large surface areas. They can provide corrosion inhibition efficiency $(\eta)$ similar to that by chemical modification of surfaces. For example, manganese-based thin films (thickness $190 \mathrm{~nm}$ ) on SS304L when tested in 3.5 wt. $\% \mathrm{NaCl}$ solution showed $\eta \approx 96 \%$ [47]. MG1 shows $\eta \geq 92 \%$ (Table 5), after long-term exposure to $3.5 \mathrm{wt}$. \% $\mathrm{NaCl}$ solution.

- Random textures (i.e., random surface roughness) on metallic surfaces provide hydrophobicity and induce anticorrosion capability [38-40]. However, micropatterning of surfaces provides the capability to control/manipulate corrosion by geometrical design.

- Superhydrophobic micropatterns with ultra-antiwetting capability can be designed to mitigate liquid mediated corrosion [10,40]. Surface features of natural water-repellent plant leaves provide inspiration and insights to design such surfaces [10,40,41]. For example, surface features on rice leaves induce anisotropic wetting characteristics to the leaves surface (water contact angles: $151^{\circ}$ across their length, $146^{\circ}$ along their length) [41]. Hierarchical surface architecture of rice leaves imparts directional motion to water droplets falling on them and forces the water droplets to roll over along their length.

- Micropatterns have multi-functionality and can be utilized for more than one purpose in combination with their anticorrosion functionality [3-5].

\section{Conclusions}

The present investigation was aimed to examine the long-term antiwetting ability of topographically modified SS304 surfaces and their efficacy to impart long-term anticorrosion ability to the steel surface in saline water. The following are the main conclusions that can be drawn from the work:

- SS304 flat surface is severely affected by salt water corrosion due to its hydrophilic nature, i.e., high surface wettability.

- Microgrooves due to their hydrophobicity reduce surface wetting by the corrosive fluid, due to their smaller surface areas via the composite solid-liquid-air interface.

- Microgrooves have high corrosion inhibition efficiency $(\eta \geq 88 \%)$ in inhibiting saline water corrosion of SS304 surface over long duration. 
- For hydrophobic micropatterns, along with their solid fraction value, the roughness on their ridges and their groove depth should also be considered for a better understanding of their surface wettability and corrosion behaviour.

- Surface wettability is an important driving factor for liquid mediated corrosion. By controlling surface wettability, liquid-mediated corrosion can be readily controlled.

- Topographical modification offers great flexibility and ease in mitigating liquidmediated corrosion via design/selection of geometrical and surface parameters. It has immense research and applicative potential in terms of long-term anticorrosion capability.

Author Contributions: Conceptualization, V.A.A. and R.A.S.; methodology, V.A.A. and R.A.S.; software, V.A.A., R.A.S., S.J., Y.Z., K.S.R. and R.S.; validation V.A.A., R.A.S. and S.J.; formal analysis, V.A.A., R.A.S. and S.J.; investigation, V.A.A. and R.A.S.; resources, V.A.A., R.A.S., S.J., Y.Z., K.S.R. and R.S.; data curation, V.A.A., R.A.S., S.J. and K.S.R.; writing—original draft preparation, R.A.S.; writing-review and editing, R.A.S. and S.J.; visualization, V.A.A., R.A.S., S.J., Y.Z., K.S.R. and R.S.; supervision, R.A.S.; project administration, V.A.A., R.A.S. and K.S.R.; All authors have read and agreed to the published version of the manuscript.

Funding: This research received no external funding.

Institutional Review Board Statement: Not applicable.

Informed Consent Statement: Not applicable.

Data Availability Statement: Data is contained within the article.

Conflicts of Interest: The authors declare no conflict of interest.

\section{References}

1. Pedeferri, P. Corrosion Science and Engineering; Springer International Publishing: New York, NY, USA, 2018.

2. Bosing, I.; Cramer, L.; Steinbacher, M.; Zoch, H.W.; Thoming, J.; Baune, M. Influence of heat treatment on the microstructure and corrosion resistance of martensitic stainless steel. AIP Adv. 2019, 9, 65317. [CrossRef]

3. Arvind Singh, R.; Kim, H.J.; Kim, J.; Yang, S.; Jeong, H.E.; Suh, K.Y.; Yoon, E.S. A biomimetic approach for effective reduction in micro-scale friction by direct replication of topography of natural water-repellent surfaces. J. Mech. Sci. Technol. 2007, 21, 624-629. [CrossRef]

4. Arvind Singh, R.; Siyuan, L.; Satyanarayana, N.; Kustandi, T.S.; Sinha, S.K. Bio-inspired polymeric patterns with enhanced wear durability for microsystem applications. Mater. Sci. Eng. C 2011, 31, 1577-1583. [CrossRef]

5. Lin, N.; Li, D.; Zou, J.; Xie, R.; Wang, Z.; Tang, B. Surface texture-based surface treatments on Ti6Al4V titanium alloys for tribological and biological applications: A mini review. Materials 2018, 11, 487. [CrossRef] [PubMed]

6. Vivek Anand, A.; Arumugam, V.; Jayalakshmi, S.; Arvind Singh, R. Innovative approach for suppressing corrosion of SS304 steel in saline water environment. Anti-Corros. Methods Mater. 2018, 65, 484-491.

7. Ruiz de Lara, L.; Jagdheesh, R.; Ocana, J.L. Corrosion resistance of laser patterned ultrahydrophobic aluminium surface. Mater. Lett. 2016, 184, 100-103. [CrossRef]

8. Toloei, A.S.; Stoilov, V.; Northwood, D.O. A new approach to combating corrosion of metallic materials. Appl. Surf. Sci. 2013, 284, 242-247. [CrossRef]

9. Trdan, U.; Hocevar, M.; Gregorcic, P. Transition from superhydrophilic to superhydrophobic state of laser textured stainless steel surface and its effect on corrosion resistance. Corros. Sci. 2017, 123, 21-26. [CrossRef]

10. Lian, Z.; Xu, J.; Yu, Z.; Yu, P.; Yu, H. A simple two-step approach for the fabrication of bio-inspired superhydrophobic and anisotropic wetting surfaces having corrosion resistance. J. Alloys Compd. 2019, 793, 326-335. [CrossRef]

11. Guo, M.; Toloei, A.; Rotermund, H.H. The effect of surface patterning on corrosion resistance of biomedical devices. J. Mater. Eng. Perform. 2016, 25, 4190-4198. [CrossRef]

12. Darmanin, T.; De Givenchy, E.T.; Amigoni, S.; Guittard, F. Superhydrophobic surfaces by electrochemical processes. Adv. Mater. 2013, 25, 1378-1394. [CrossRef]

13. Han, D.S.; Kang, Q.; Ko, T.J.; Park, J.K. Surface texturing by using patterned grinding wheel. In Proceedings of the 5th International \& 26th All India Manufacturing Technology, Design and Research Conference (AIMTDT 2014), Guwahati, India, 12-14 December 2014; pp. 1-3.

14. Bae, W.G.; Kim, D.; Song, K.Y.; Jeong, H.E.; Chu, C.N. Engineering stainless steel surface via wire electrical discharge machining for controlling the wettability. Surf. Coat. Technol. 2015, 275, 316-323. [CrossRef]

15. Guo, P.; Lu, Y.; Ehmann, K.F.; Cao, J. Generation of hierarchical micro-structures for anisotropic wetting by elliptical vibration cutting. CIRP Ann.-Manuf. Technol. 2014, 63, 553-556. [CrossRef] 
16. Vaezi, M.; Drescher, P.; Seitz, H. Beamless metal additive manufacturing. Materials 2020, 13, 922. [CrossRef]

17. International Stainless Steel Forum. Available online: https://www.worldstainless.org (accessed on 12 September 2021).

18. Kim, J.; Sim, S.O.; Park, H.W. Fabrication of durable hydrophobic micropatterns on stainless steel using a hybrid irradiation process. Surf. Coat. Technol. 2016, 302, 535-542. [CrossRef]

19. Morales, D.M.; Cecilia, C.A. Determination of the corrosion resistance of SS-304 in synthetic seawater at two temperatures using electrochemical noise and polarization curves. Int. J. Electrochem. Sci. 2016, 11, 8683-8696. [CrossRef]

20. Abu Qudeiri, J.E.; Saleh, A.; Ziout, A.; Mourad, A.H.I.; Abidi, M.H.; Elkaseer, A. Advanced electric discharge machining of stainless steels: Assessment of the state of the art, gaps and future prospect. Materials 2019, 12, 907. [CrossRef]

21. Revie, R.W.; Uhlig, H.H. Corrosion and Corrosion Control; John Wiley \& Sons: Hoboken, NJ, USA, 2008.

22. Bhushan, B.; Jung, Y.C.; Koch, K. Self-cleaning efficiency of artificial superhydrophobic surfaces. Langmuir 2009, 25, 3240-3248. [CrossRef]

23. Law, K.Y.; Zhao, H. Surface Wetting; Springer International Publishing: New York, NY, USA, 2016.

24. Gui, N.; Xu, W.; Tian, J.; Rosengarten, G.; Brandt, M.; Qian, M. Fabrication and anisotropic wettability of titanium-coated microgrooves. J. Appl. Phys. 2018, 123, 95306. [CrossRef]

25. Asaduzzaman, M.; Mustafa, C.M.; Islam, M. Effects of concentration of sodium chloride on the pitting corrosion behaviour of AISI-304L austenitic stainless steel. Chem. Ind. Chem. Eng. Q. 2011, 17, 477-483. [CrossRef]

26. Hoar, T.P.; Mears, D.C.; Othwell, G.P. The relationships between anodic passivity, brightening and pitting. Corros. Sci. 1965, 5, 279-289. [CrossRef]

27. Fontana, M.G. Corrosion Engineering; McGraw-Hill Book Company: New York, NY, USA, 1987.

28. Bormashenko, E. Wetting transitions on biomimetic surfaces. Philos. Trans. R. Soc. A 2010, 368, 4695-4711. [CrossRef] [PubMed]

29. Bhushan, B.; Jung, Y.C.; Nosonovsky, M. Lotus Effect: Surfaces with roughness-induced superhydrophobicity, self-cleaning, and low adhesion. In Springer Handbook of Nanotechnology; Springer: Heidelberg/Berlin, Germany, 2010; pp. 1437-1524.

30. Herminghaus, S. Roughness-induced wetting. Europhys. Lett. 2000, 52, 165-170. [CrossRef]

31. Loto, R.T. Pitting corrosion resistance and inhibition of lean austenitic stainless steel alloys, Chapter 8. In Austenitic Stainless Steels-New Aspects; IntechOpen: London, UK, 2017; pp. 147-170.

32. Tang, Y.; Zuo, Y.; Wang, J.; Zhao, X.; Niu, B.; Lin, B. The metastable pitting potential and its relation to the pitting potential for four materials in chloride solutions. Corros. Sci. 2014, 80, 111-119. [CrossRef]

33. Fallleiros, N.A.; Wolynec, S. Correlation between corrosion potential and pitting potential for AISI 304L austenitic stainless steel in 3.5\% $\mathrm{NaCl}$ aqueous solution. Mater. Res. 2002, 5, 77-84. [CrossRef]

34. Reimbrecht, E.G.; Bazzo, E.; Almeida, L.H.S.; Silva, H.C.; Binder, C.; Muzart, J.L.R. Manufacturing of metallic porous structures to be used in capillary pumping systems. Mater. Res. 2003, 6, 481-486. [CrossRef]

35. Tong, W.; Karthik, N.; Li, J.; Wang, N.; Xiong, D. Superhydrophobic surface with stepwise multilayered micro- and nanostructure and an investigation of its corrosion resistance. Langmuir 2019, 35, 15078-15085. [CrossRef]

36. Qiu, R.; Li, Z.; Wu, Z. Enhanced anti-icing and anti-corrosion properties of wear-resistant superhydrophobic surfaces based on $\mathrm{Al}$ alloys. Mater. Res. Express 2019, 6, 45059. [CrossRef]

37. Bae, W.G.; Song, K.Y.; Rahmawan, Y.; Chu, C.N.; Kim, D.; Chung, D.K.; Suh, K.Y. One-step process for superhydrophobic metallic surfaces by wire electrical discharge machining. Appl. Mater. Interfaces 2012, 4, 3685-3691. [CrossRef]

38. Zhao, E.; Li, Y.; Gao, L.; Yang, S.; Ma, T. Anti-corrosion properties of a bioinspired superhydrophobic surface on stainless steel. Int. J. Electrochem. Sci. 2017, 12, 9855-9864. [CrossRef]

39. Zhang, B.; Xu, W.; Zhu, Q.; Yuan, S.; Li, Y. Lotus-inspired multiscale superhydrophobic AA5083 resisting surface contamination and marine corrosion attack. Materials 2019, 12, 1592. [CrossRef]

40. Yao, C.W.; Sebastian, D.; Lian, I.; Günaydın-Sen, Ö.; Clarke, R.; Clayton, K.; Chen, C.Y.; Kharel, K.; Chen, Y.; Li, Q. Corrosion resistance and durability of superhydrophobic copper surface in corrosive $\mathrm{NaCl}$ aqueous solution. Coatings 2018, 8, 70. [CrossRef]

41. Jia, Y.; JianNan, W.; YanHao, Y.; Han, Y.; Ying, X. Biomimetic fabrication and characterization of an artificial rice leaf surface with anisotropic wetting. Chin. Sci. Bull. 2012, 57, 2631-2634.

42. Fang, C.Z.; Pei, Q.; Pei, C.; Xin, W.; Yi, L.G.; Shuai, W.; Hong, Z. Super-hydrophobic coating used in corrosion protection of metal material: Review, discussion and prospects. Metall. Res. Technol. 2017, 114, 203. [CrossRef]

43. Lia, Y.; Zhang, X.; Cui, Y.; Wang, H.; Wang, J. Anti-corrosion enhancement of superhydrophobic coating utilizing oxygen vacancy modified potassium titanate whisker. Chem. Eng. J. 2019, 374, 1326-1336. [CrossRef]

44. Abdeen, D.H.; Hachach, M.E.; Koc, M.; Atieh, M.A. A review on the corrosion behaviour of nanocoatings on metallic substrates. Materials 2019, 12, 210. [CrossRef]

45. Ijaola, A.O.; Farayibi, P.K.; Asmatulu, E. Superhydrophobic coatings for steel pipeline protection in oil and gas industries: A comprehensive review. J. Nat. Gas Sci. Eng. 2020, 83, 103544. [CrossRef]

46. Sanni, O.; Fayomi, O.S.I.; Popoola, A.P.I. Eco-friendly inhibitors for corrosion protection of stainless steel: An overview, International Conference on Engineering for Sustainable World. J. Phys. Conf. Ser. 2019, 1378, 42047. [CrossRef]

47. Modiri, F.; Savaloni, H. Anti-corrosion properties of stainless steel 304L coated with Mn-based thin film and annealed with nitrogen flux exposed to saline solution under various temperatures. J. Theor. Appl. Phys. 2020, 14, 223-236. [CrossRef] 